\title{
Fertilidade do solo, nutrição mineral e produtividade da bananeira irrigada por dez anos
}

\author{
Luiz Arnaldo Fernandes(1), Sílvio Júnio Ramos(2), Samuel Vasconcelos Valadares ${ }^{(1)}$, \\ Paulo Sergio Nascimento Lopes ${ }^{(1)}$ e Valdemar Faquin ${ }^{(2)}$
}

\begin{abstract}
(1)Universidade Federal de Minas Gerais, Instituto de Ciências Agrárias, Avenida Osmani Barbosa, s/no, Caixa Postal 135, CEP 39404-006 Montes Claros, MG. E-mail: larnaldo@nca.ufmg.br, samucavaladares@yahoo.com.br, psnlopes@nca.ufmg.br(2)Universidade Federal de Lavras, Departamento de Ciência do Solo, CEP 37200-000 Lavras, MG. E-mail: silviojramos@gmail.com, vafaquin@ufla.br
\end{abstract}

\begin{abstract}
Resumo - O objetivo deste trabalho foi avaliar as alterações na fertilidade do solo, na nutrição mineral e na produtividade de bananeira irrigada por dez anos. O experimento foi conduzido em Latossolo Vermelho eutrófico, de 1997 a 2007, no Município de Janaúba, MG, em um plantio comercial de banana 'Prata-Anã', onde se utilizam, para irrigação por gotejamento, água calcária de poço tubular com salinidade alta e concentração média de sódio. Observou-se que a aplicação da irrigação, por dez anos, promove forte elevação no pH e na condutividade elétrica do solo e desequilíbrios nutricionais, o que limita a produtividade da bananeira. Os teores foliares de macro e micronutrientes permanecem acima dos valores de referência para a cultura.
\end{abstract}

Termos para indexação: Musa spp., análise do solo, atributo químico, gotejamento, poço tubular, salinidade.

\section{Soil fertility, plant mineral nutrition and productivity of irrigated banana for a ten-year period}

\begin{abstract}
The objective of this study was to evaluate changes in soil fertility, in plant mineral nutrition and in the productivity of banana irrigated for a ten-year period. The experiment was carried out in an Oxisol, from 1997 to 2007, in the county of Janaúba, Minas Gerais, Brazil, in a commercial banana 'Prata-Anã' (AAB) plantation, where water from a tubular deep-well - containing high salinity and medium concentration of sodium - was used for drip irrigation. The use of irrigation for ten years promotes a sharp rise in $\mathrm{pH}$ and in soil electrical conductivity, and causes nutrient imbalances, which limits the productivity of banana. The foliar levels of macro and micronutrientes remain above the reference values for the culture.
\end{abstract}

Index terms: Musa, soil analysis, chemical attributes, drip irrigation, tubular deep-well, salinity.

\section{Introdução}

A agricultura irrigada apresenta o maior consumo de água entre os diversos usuários deste recurso natural, chegando, em muitos países, a constituir $80 \%$ do consumo total. No Brasil, estima-se que mais da metade da água consumida ocorre na agricultura irrigada. Segundo Silva et al. (1999), a utilização de água de má qualidade pode aumentar o $\mathrm{pH}$ no solo e promover desequilíbrio nutricional na bananeira, que é muito sensível ao desbalanço entre $\mathrm{Ca}, \mathrm{K} \mathrm{e} \mathrm{Mg}$.

A bananeira (Musa spp.) é uma planta de grande importância socioeconômica no mundo, com o mais alto índice de consumo per capita entre as frutas tropicais, e com um comércio tradicional consolidado e bem distribuído (Brasil, 2008). Dados coletados, durante 40 anos de observação pela FAO (2004), revelam que o consumo de banana mundial per capita cresceu $72 \%$, nesse período.

O Brasil se destaca como um dos países com maior produção de bananas, embora a qualidade do produto normalmente apresente limitação para exportação. A exploração em condições irrigadas tem sido a solução para os locais em que as precipitações não são suficientes para suprir as necessidades hídricas da bananeira (FAO, 2004). A região norte do Estado de Minas Gerais é uma grande produtora de banana irrigada, em razão da baixa precipitação anual e da alta taxa de evapotranspiração, em que a produção comercial só é possível quando se faz uso da irrigação. No entanto, o uso de águas de irrigação ricas em carbonato de cálcio, em bananais do norte de Minas Gerais, tem provocado alterações nas características químicas dos solos, com elevação do $\mathrm{pH}$ e dos teores

Pesq. agropec. bras., Brasília, v.43, n.11, p.1575-1581, nov. 2008 
de cálcio e sódio, como relatado por Silva et al. (2007) e Nunes et al. (2008).

O objetivo deste trabalho foi avaliar as alterações na fertilidade do solo, na nutrição mineral e na produtividade da bananeira irrigada por dez anos.

\section{Material e Métodos}

O experimento foi conduzido durante dez anos (1997 a 2007), em um Latossolo Vermelho eutrófico, de textura argilosa, fase caatinga hipoxerófila, relevo suave-ondulado, com declives de 3 a 5\%, no Município de Janaúba, norte de Minas Gerais a 15²51'47,5"S e $43^{\circ} 25^{\prime} 27,8^{\prime \prime} \mathrm{W}$.

Em setembro de 1997, as mudas de bananeira, cultivar Prata-Anã [Musa sp. (AAB)], provenientes de cultura de tecidos, foram plantadas em campo. O preparo do solo constou de aração, gradagem e abertura de covas de plantio de $50 \times 50 \times 50 \mathrm{~cm}$, com auxílio de enxada. A análise química e física do solo, antes da adubação de plantio das mudas, na camada 0-20 cm, realizada de acordo com Embrapa (1997), apresentou os seguintes resultados: $\mathrm{pH} \mathrm{em} \mathrm{H}_{2} \mathrm{O}(1: 2,5)$ 5,48; Ca, 5,76 $\mathrm{cmol}_{\mathrm{c}} \mathrm{dm}^{-3} ; \mathrm{Mg}, 1,74 \mathrm{cmol}_{\mathrm{c}} \mathrm{dm}^{-3}$; $\mathrm{Al}, \quad 0,0 \quad \mathrm{cmol}_{\mathrm{c}} \quad \mathrm{dm}^{-3} ; \mathrm{H}+\mathrm{Al}, \quad 2,71 \quad \mathrm{cmol}_{\mathrm{c}} \quad \mathrm{dm}^{-3}$; $\mathrm{P}$ (Mehlich 1), 2,59 $\mathrm{mg} \mathrm{dm}^{-3} ; \mathrm{K}, 158,42 \mathrm{mg} \mathrm{dm}^{-3} ; \mathrm{Fe}$, $20,97 \mathrm{mg} \mathrm{dm}^{-3} ; \mathrm{Cu}, 1,31 \mathrm{mg} \mathrm{dm}^{-3} ; \mathrm{Zn}, 10,34 \mathrm{mg} \mathrm{dm}^{-3}$; $\mathrm{Mn}, 176,28 \mathrm{mg} \mathrm{dm}{ }^{-3}$; B, 0,85 $\mathrm{mg} \mathrm{dm}^{-3}$; MOS, 1,77 dag $\mathrm{kg}^{-1}$; argila, 54 dag $\mathrm{kg}^{-1}$; silte 15 dag $\mathrm{kg}^{-1}$; areia, $31 \mathrm{dag}^{\mathrm{kg}}{ }^{-1}$.

Para a adubação de plantio, utilizaram-se $200 \mathrm{~g}$ de NPK comercial 5-25-15, mais $60 \mathrm{~g}$ de FTE BR-12 (18 $\mathrm{g} \mathrm{kg}^{-1}$ de B; $8 \mathrm{~g} \mathrm{~kg}^{-1}$ de $\mathrm{Cu} ; 30 \mathrm{~g} \mathrm{~kg}^{-1}$ de Fe; $20 \mathrm{~g} \mathrm{~kg}^{-1}$ de $\mathrm{Mn}$; $1 \mathrm{~g} \mathrm{~kg}^{-1}$ de Mo; e $9 \mathrm{~g} \mathrm{~kg}^{-1}$ de $\mathrm{Zn}$ ), por cova, conforme recomendação de Souza et al. (1999) para bananeira 'Prata-Anã'. A primeira adubação de cobertura foi feita com a aplicação de $200 \mathrm{~g}$ de sulfato de amônio, $200 \mathrm{~g}$ de cloreto de potássio, $20 \mathrm{~g}$ de bórax e $30 \mathrm{~g}$ de sulfato de zinco, por planta, três meses após o plantio, ao redor da planta-mãe. As adubações de cobertura subseqüentes foram realizadas em intervalos de três meses, com as mesmas doses de sulfato de amônio e de cloreto de potássio. As aplicações de $\mathrm{P}\left(50 \mathrm{~g}\right.$ de $\mathrm{P}_{2} \mathrm{O}_{5}$ por cova, com uso de superfosfato simples) e micronutrientes (50 $\mathrm{g}$ de FTE BR-12 por cova) foram repetidas a cada seis meses. $\mathrm{Na}$ primeira safra, as adubações de cobertura foram realizadas ao redor da família (planta mãe, uma plantafilha e uma planta-neta); nas demais, em semicírculo ao lado da planta-filha.
Após a primeira adubação de cobertura, foi realizada uma subsolagem nas entrelinhas, a $50 \mathrm{~cm}$ de profundidade, para auxiliar a penetração do sistema radicular das plantas. A operação foi realizada com um subsolador de duas hastes, a 0,50 $\mathrm{m}$ da linha de plantio. A condução do pomar foi feita por meio do desbaste, utilizando-se o sistema de família, que consiste em manter a planta-mãe com uma planta-filha e uma planta-neta, eliminando-se as demais.

Utilizou-se, para irrigação da cultura, água de poço tubular, classificada como $\mathrm{C}_{3} \mathrm{~S}_{1}$ - água com salinidade alta e concentração média de sódio, de acordo com Maia et al. (1998), com as seguintes características químicas, determinadas conforme Embrapa (1997): $\mathrm{pH}, \quad 6,9 ;$ condutividade elétrica, 1,64 dS $\mathrm{m}^{-1}$; $\mathrm{Ca}^{2+}, 13,5 \mathrm{mmol}_{\mathrm{c}} \mathrm{L}^{-1} ; \mathrm{Mg}^{2+}, 4,3 \mathrm{mmol}_{\mathrm{c}} \mathrm{L}^{-1} ; \mathrm{Na}^{+}$, $32,2 \mathrm{mmol}_{\mathrm{c}} \mathrm{L}^{-1} ; \mathrm{Cl}^{-}, 6,8 \mathrm{mmol}_{\mathrm{c}} \mathrm{L}^{-1} ; \mathrm{CO}_{3}{ }^{2-}, 0,0$ mmol $_{\mathrm{c}} \mathrm{L}^{-1}$; $\mathrm{HCO}_{3}^{-}, 17 \mathrm{mmol}_{\mathrm{c}} \mathrm{L}^{-1}$. A relação de adsorção de sódio (RAS), conforme Yaron (1973), apresentou o valor $10,80 \mathrm{mmol}_{\mathrm{c}} \mathrm{L}^{-1}$.

O sistema de irrigação utilizado, inspecionado anualmente, foi o de gotejamento, com duas linhas laterais por fileira e quatro gotejadores por planta, com turno de rega de dois dias, o que manteve a umidade do solo próxima à capacidade de campo, com a lâmina de água aplicada correspondente a $120 \%$ da evapotranspiração de referência (ETo), estimada pela equação de Penman-Monteith, conforme Figueiredo et al. (2006) para a irrigação da bananeira 'Prata-Anã', no norte do Estado de Minas Gerais.

As alterações na fertilidade do solo e na nutrição e produtividade da bananeira, com a irrigação de poço tubular, foram acompanhadas por dez anos. Para tal, utilizaram-se oito unidades experimentais de $440 \mathrm{~m}^{2}$ (22 $\mathrm{m}$ de comprimento e $20 \mathrm{~m}$ de largura), de onde, em cada ano, foram coletadas 15 amostras de solo, para cada unidade experimental. Para o acompanhamento da produtividade e teor foliar dos nutrientes, utilizaramse 15 plantas úteis em cada parcela. Adotou-se a mudança de tonalidade da casca, de verde-escuro para verde-claro, como critério para a definição da época de colheita dos cachos. As amostras de solos, retiradas para acompanhar as alterações nos atributos químicos ao longo do tempo, foram feitas à profundidade de 0-20 cm, na projeção da copa da planta-filha, coletadas no mês de maio de cada ano e analisadas conforme metodologia da Embrapa (1997). 
As coletas das folhas, realizadas para acompanhar as alterações no teor foliar de nutrientes na bananeira, ao longo do tempo, foram realizadas anualmente, quando a planta estava iniciando a emissão do cacho. As amostras foram coletadas na terceira folha, a partir do ápice, tendo sido retirados os $10 \mathrm{~cm}$ da parte central do limbo de cada folha, com descarte da nervura central (Teixeira et al., 1997). Essas amostras de folhas foram analisadas para a determinação dos teores de nutrientes (Malavolta et al., 1997).

Os resultados obtidos foram submetidos à análise de variância, pelo programa SISVAR (Ferreira, 1999). Foram ajustadas equações de regressão polinomial para as variáveis analisadas como função do tempo de plantio das bananeiras em campo (variável independente), e feitas análises de correlação de Pearson entre a produtividade da cultura e os teores de nutrientes no solo e no tecido foliar.

\section{Resultados e Discussão}

As análises do solo revelaram variações significativas nos valores de acidez ativa ( $\mathrm{pH}$ em água), acidez potencial $(\mathrm{H}+\mathrm{Al})$, matéria orgânica do solo (MOS), condutividade elétrica (CE), Ca, Mg, K, P, Mn, Fe e Zn, no período estudado. No entanto, não foram verificadas variações significativas nos teores de $\mathrm{B}$ e $\mathrm{Cu}$.

Para o pH, MOS e CE do solo, observaram-se aumentos lineares, ao longo dos dez anos de avaliação, enquanto os valores de $\mathrm{H}+\mathrm{Al}$ diminuíram linearmente (Figura 1). Entre o primeiro e o décimo ano de avaliação, os valores de $\mathrm{pH}$ variaram de 5,53 a 8,39; os de MOS, de 1,87 a 3,64 $\mathrm{mg} \mathrm{kg}^{-1}$; e os de CE, de 0,86 a 2,16 $\mathrm{ds} \mathrm{m}^{-1}$. O aumento dos valores de $\mathrm{pH}$ e de $\mathrm{CE}$ do solo se deve, provavelmente, à irrigação com água calcária, rica em carbonatos $\left(\mathrm{CO}_{3}^{-}\right)$e bicarbonatos $\left(\mathrm{HCO}_{3}^{-}\right)$, e com elevada condutividade elétrica. $\mathrm{O}$ incremento no teor de matéria orgânica no solo pode ser atribuído ao aporte de material orgânico, folhas e pseudocaules da bananeira, depositados na superfície do solo ao longo dos dez anos de cultivo. Da mesma forma, Silva et al. (2001), ao avaliar o estado nutricional da cultura da banana irrigada com água subterrânea, no norte de Minas Gerais, verificaram aumento dos valores de $\mathrm{pH}$ do solo e o relacionaram à qualidade da água de irrigação. Esses autores também verificaram aumento do teor de MOS e relataram que dois terços da parte aérea produzida pela bananeira, durante o seu ciclo vegetativo, retornam ao solo em forma de pseudocaules e folhas, o que pode representar um aporte de 10 a $15 \mathrm{Mg} \mathrm{ha}^{-1}$ de matéria seca, por ano. Os resultados deste trabalho corroboram os de Moreira et al. (2007) que, ao avaliar a densidade de plantio na produtividade e nos teores de nutrientes, em folhas e frutos de bananeira, observaram incremento da MOS já no segundo ciclo da cultura.

A redução linear nos valores de $\mathrm{H}+\mathrm{Al}$, com o aumento do $\mathrm{pH}$ observado ao longo do tempo, pode ser atribuída à neutralização direta dos íons $\mathrm{H}^{+}$, adsorvidos na fase sólida do solo, pelos íons $\mathrm{OH}^{-}$(Quaggio, 2000), e pela ocupação dos sítios de troca pelo cátion acompanhante dos carbonatos e bicarbonatos adicionados via água de irrigação (Figura 1). A acidez trocável $\left(\mathrm{Al}^{3+}\right)$ do solo foi nula, durante todo o período experimental, fato que pode ser atribuído ao elevado $\mathrm{pH}$ e ao material de origem do solo, uma vez que, mesmo antes do cultivo da bananeira, não foi constada a presença desse elemento no solo. Segundo Embrapa (1979), os solos da região se originam de rochas calcárias do grupo Bambuí, com altas concentrações de $\mathrm{CaCO}_{3}$ precipitado e $\mathrm{HCO}_{3}$ em solução, $\mathrm{pH}$ elevado e ausência de $\mathrm{Al}^{3+}$ trocável.

Para os valores de macronutrientes, observou-se aumento linear nos teores de $\mathrm{Ca}, \mathrm{Mg}$ e $\mathrm{P}$, enquanto os de $\mathrm{K}$ reduziram de forma quadrática. De maneira geral, a média dos valores, tanto para o Ca quanto o

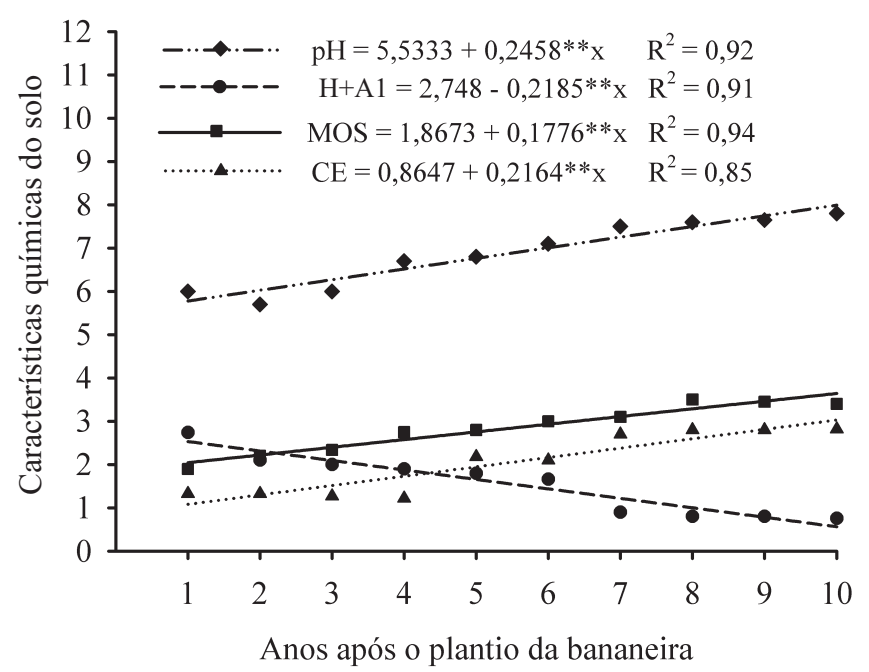

Figura 1. Variação do $\mathrm{pH}(1: 2,5)$, acidez potencial $(\mathrm{H}+\mathrm{Al})$ $\left(\mathrm{cmol}_{\mathrm{c}} \mathrm{dm}^{-3}\right)$, matéria orgânica do solo (MOS) $\left(\right.$ dag $\left.\mathrm{kg}^{-1}\right) \mathrm{e}$ condutividade elétrica do solo $(\mathrm{CE})\left(\mathrm{dS} \mathrm{m} \mathrm{m}^{-1}\right)$, ao longo dos anos após o plantio da bananeira. 
$\mathrm{Mg}$ e P, triplicaram em relação ao valor inicial. Os de Ca passaram de 4,46 para $14,64 \mathrm{cmol}_{\mathrm{c}} \mathrm{dm}^{-3}$, os de $\mathrm{Mg}$ de 1,22 para 3,19 $\mathrm{cmol}_{\mathrm{c}} \mathrm{dm}^{-3}$ e os $\mathrm{P}$ de 1,19 para $5,01 \mathrm{mg} \mathrm{dm}^{-3}$ (Figura 2). Esses resultados podem ser explicados pelo uso de água calcária nas irrigações, que continha $\mathrm{Ca}$ e $\mathrm{Mg}$, e pelas adubações fosfatadas anuais, que aumentaram a disponibilidade desses nutrientes para as plantas.

Para o $\mathrm{P}$, além da adição do nutriente com a adubação, o aumento do valor de $\mathrm{pH}$ do solo pode ter impedido a ocorrência da reação do $\mathrm{H}_{2} \mathrm{PO}_{4}^{-}$com as formas iônicas de $\mathrm{Fe}$ e $\mathrm{Al}$, e diminuído a possibilidade de adsorção específica do fosfato na fase sólida do solo. Todavia, pode ter ocorrido a precipitação de $\mathrm{P}$ na forma de $\mathrm{Ca}_{3}\left(\mathrm{PO}_{4}\right)_{2}$ e adsorção ao $\mathrm{CaCO}_{3}$, em razão do elevado $\mathrm{pH}$ e das altas concentrações de $\mathrm{Ca}^{2+}$ e carbonatos observadas no solo (Wang \& Tzou, 1995). Nesse caso, como o extrator de P utilizado foi o Mehlich 1, que tem grande eficiência em recuperar $\mathrm{P}$ ligado ao cálcio, pode ter ocorrido superestimação da disponibilidade de $\mathrm{P}$, uma vez que essa forma de $\mathrm{P}$ não está prontamente disponível às plantas, à exceção daquelas que promovem acidificação em sua rizosfera, o que não acontece com a cultura da bananeira (Nunes et al., 2008).

Ao longo dos dez anos de avaliação, os teores de $\mathrm{Ca}$ no solo foram sempre maiores do que os de $\mathrm{Mg}$. Isso era esperado pela série de retenção de cátions que determina que o Ca é mais fortemente retido na

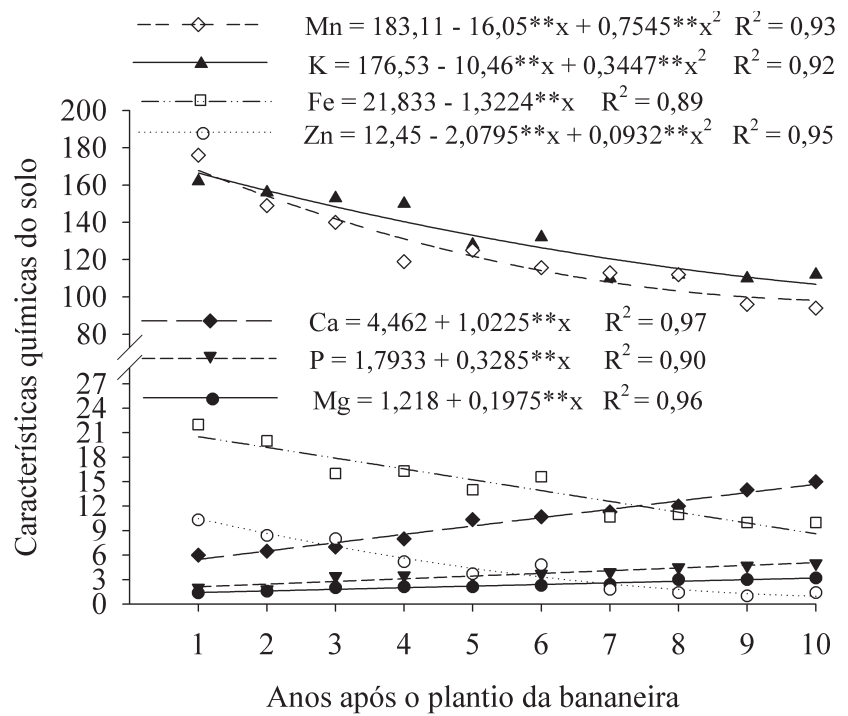

Figura 2. Variação das características químicas do solo (P, K, Fe, Zn, Mn, em mg dm${ }^{-3}$; Ca e $\mathrm{Mg} \mathrm{em} \mathrm{cmol}_{\mathrm{c}} \mathrm{dm}^{-3}$ ), ao longo dos anos após o plantio da bananeira. matriz coloidal do solo do que o Mg (Quaggio, 2000) - e também pela maior quantidade aplicada de Ca com a água de irrigação. Nunes et al. (2008), ao estudar as características químicas e físicas de solos da região de Janaúba, irrigados com água de poços tubulares e do Rio Gorutuba, encontraram resultados semelhantes. Os autores atribuíram o aumento dos teores de $\mathrm{Ca}$, nas áreas irrigadas com água dos poços tubulares, aos elevados teores desse nutriente na água de irrigação.

$\mathrm{O}$ teor de $\mathrm{K}$ no solo, no primeiro ano de avaliação, foi de $176,53 \mathrm{mg} \mathrm{dm}^{-3}$, e atingiu o valor mínimo de 104,60 $\mathrm{mg} \mathrm{dm}^{-3}$ no décimo ano (Figura 2). O deslocamento do $\mathrm{K}$ do complexo sortivo do solo, provocado por $\mathrm{Ca}^{2+}$ e $\mathrm{Mg}^{2+}$ (Quaggio, 2000), mais abundantes na água de irrigação, pode explicar esse resultado, que também foi observado por Nunes et al. (2008). A redução nos teores de $\mathrm{K}$ pode ainda ser atribuída à exportação pelos frutos, uma vez que a bananeira é uma cultura muito exigente nesse nutriente, o qual se concentra, em grande parte, nos frutos (Fontes et al., 2003). Apesar da redução de 58\% entre os valores dos teores de $\mathrm{K}$ presentes no solo, entre o primeiro e o décimo ano de avaliação, de acordo com Alvares Venegas et al. (1999), o solo ainda poderia ser classificado como de muito boa fertilidade no que se refere ao teor de $\mathrm{K}$ trocável.

Os valores dos micronutrientes $\mathrm{B}$ e $\mathrm{Cu}$ do solo não variaram significativamente, e as médias dos valores no período estudado foram de $0,61 \mathrm{e} 0,98 \mathrm{mg} \mathrm{dm}^{-3}$, respectivamente. Os teores de $\mathrm{Mn}$ e $\mathrm{Zn}$ do solo diminuíram, segundo função quadrática, e os de Fe segundo função linear (Figura 2). Os teores de Mn variaram de 183,11 a 98,16 $\mathrm{mg} \mathrm{dm}^{-3}$, os de Fe de 21,83 a 8,61 $\mathrm{mg} \mathrm{dm}^{-3}$ e os de $\mathrm{Zn}$ de 12,45 a $0,98 \mathrm{mg} \mathrm{dm}^{-3}$. A diminuição na concentração de micronutrientes no solo, com o aumento do $\mathrm{pH}$, é amplamente relatada na literatura (Silva et al., 2007 e Nunes et al., 2008). Já o boro tem sua disponibilidade aumentada até certo valor de $\mathrm{pH}$ quando, então, se formam compostos com a matéria orgânica de baixa solubilidade (Rosolem \& Bíscaro, 2007). No caso do Zn, Vale et al. (1997) complementam que o Ca adicionado ao solo é um potente deslocador do $\mathrm{Zn}$ de complexos e quelatos, e pode deixá-lo livre na solução do solo, o que favoreceria sua precipitação na forma de $\mathrm{Zn}(\mathrm{OH})_{2}$.

A maior produtividade observada foi de $18,2 \mathrm{Mg} \mathrm{ha}^{-1}$, no sexto ano de cultivo (Figura 3). Entretanto, esse 
valor é muito inferior aos observados na região, que costumam ser superiores a $30 \mathrm{Mg} \mathrm{ha}^{-1}$, em bananeira 'Prata-Anã' irrigada com água do Rio São Francisco ou do Rio Gorutuba (Nunes et al., 2008). Provavelmente, a baixa produtividade observada ocorreu, principalmente, em razão das alterações provocadas no $\mathrm{pH}$ e na condutividade elétrica do solo, pela irrigação (Figura 1), com conseqüentes alterações na disponibilidade de nutrientes. Em condições de $\mathrm{pH}$ do solo inferior a sete e baixa condutividade elétrica do solo, Pereira et al. (2000) obtiveram produção de 29,1 $\mathrm{Mg} \mathrm{ha}^{-1}$ de bananeira 'Prata-Anã'. Entretanto, Abreu et al. (1982) constataram redução de 40\% na produtividade, com o aumento da condutividade elétrica do solo. Carmo et al. (2003) relatam redução no crescimento e na produtividade da bananeira, cultivada em diferentes níveis de salinidade em água de irrigação. De acordo com Silva et al. (2002), a bananeira apresenta bom desenvolvimento em solo com CE de até $1 \mathrm{dS}$ $\mathrm{m}^{-1}$; acima desse valor, ocorre comprometimento da produção. Segundo esses autores, o aumento da $\mathrm{CE}$, até o limite tolerado pela bananeira, favorece o melhor desenvolvimento das raízes da cultura e aumenta seu potencial de absorção de água e nutrientes.

Quanto às relações $\mathrm{Ca} / \mathrm{Mg}, \mathrm{Ca} / \mathrm{Ke} \mathrm{Mg} / \mathrm{K}$, observouse aumento ao longo do período avaliado (Figura 4). A relação $\mathrm{Mg} / \mathrm{K}$ aumentou de forma quadrática, e passou de 3,28:1, no primeiro ano de avaliação, para 10,90:1, no décimo ano. As relações $\mathrm{Ca} / \mathrm{K}$ e $\mathrm{Ca} / \mathrm{Mg}$ apresentarem comportamento linear. Entre o primeiro e o décimo ano de avaliação, a relação

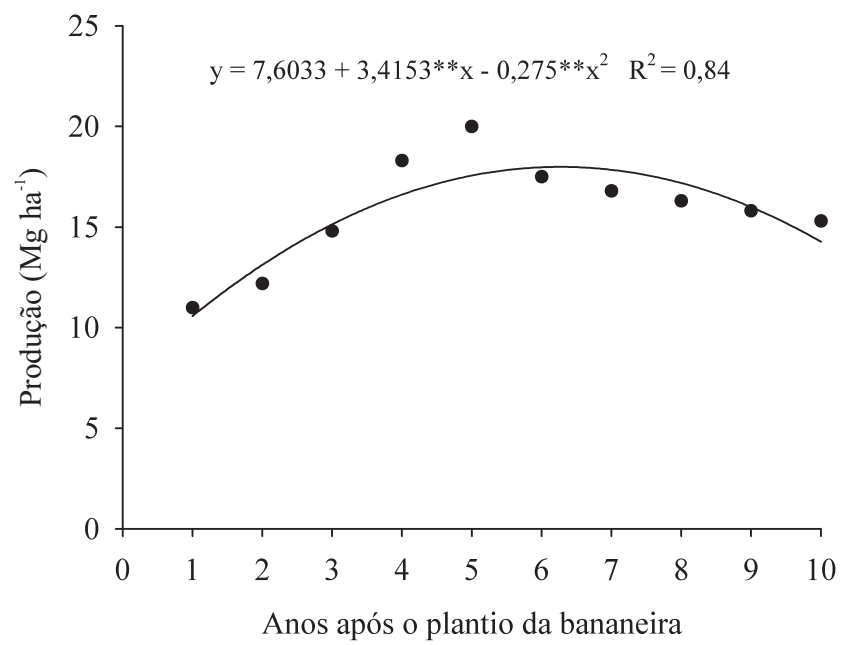

Figura 3. Variação da produção da bananeira cultivar Prata-Anã, ao longo dos anos após o plantio.
$\mathrm{Ca} / \mathrm{K}$ variou de 11,18:1 a 51,77:1, e a relação $\mathrm{Ca} / \mathrm{Mg}$, de 4,06:1 a 4,60:1. O aumento nas relações $\mathrm{Mg} / \mathrm{K}$ e $\mathrm{Ca} / \mathrm{K}$ ao longo dos anos se deve à maior retenção de $\mathrm{Ca}^{2+}$ e $\mathrm{Mg}^{2+}$ no solo e ao maior aporte desses nutrientes via água de irrigação, em relação ao K. Segundo Silva et al. (1999), a relação Ca/Mg adequada para a bananeira 'Prata-Anã' situa-se entre 1,5:1 e $3: 1$, e a relação $\mathrm{Ca} / \mathrm{K}$, entre $0,14: 1$ e $0,17: 1$, muito menores do que as observadas neste trabalho.

De maneira geral, os resultados encontrados no presente trabalho, para a relação $\mathrm{Ca} / \mathrm{Mg}$ e $\mathrm{Ca} / \mathrm{K}$, foram inferiores aos encontrados por Nunes et al. (2008), em razão, principalmente, dos diferentes solos e qualidade da água utilizados nos dois estudos.

Os teores dos nutrientes, na matéria seca foliar, seguiram a seguinte ordem de concentração: $\mathrm{K}>\mathrm{N}>\mathrm{Ca}>\mathrm{Mg}>\mathrm{S}>\mathrm{P}>\mathrm{Mn}$ (Figura 5), semelhante à encontrada por Fontes et al. (2003) e Silva et al. (2007). Esses autores mencionam que a bananeira, independentemente da cultivar, extrai maiores quantidades de $\mathrm{K}$ que dos demais nutrientes. Embora os teor es foliares de nutrientes tenham se apresentado acima dos valores de referência para a cultura (Martinez et al., 1999), os desequilíbrios nutricionais e a alta condutividade elétrica do solo podem ter comprometido a produtividade, a partir do sexto ano de avaliação.

De modo geral, não foram verificadas correlações significativas entre os teores de nutrientes do solo e os das folhas, e nem entre os teores de nutrientes (do solo e da folha) e a produtividade da bananeira (Tabela 1), o que reforça a hipótese de que o desequilíbrio

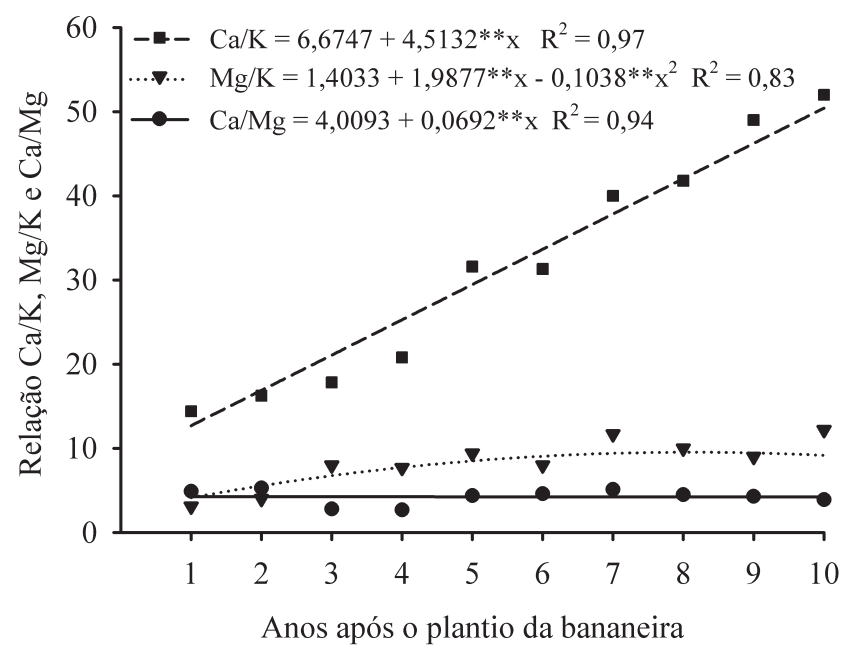

Figura 4. Relação $\mathrm{Ca} / \mathrm{K}, \mathrm{Mg} / \mathrm{K}$ e $\mathrm{Ca} / \mathrm{Mg}$ do solo, ao longo dos anos após o plantio da bananeira. 


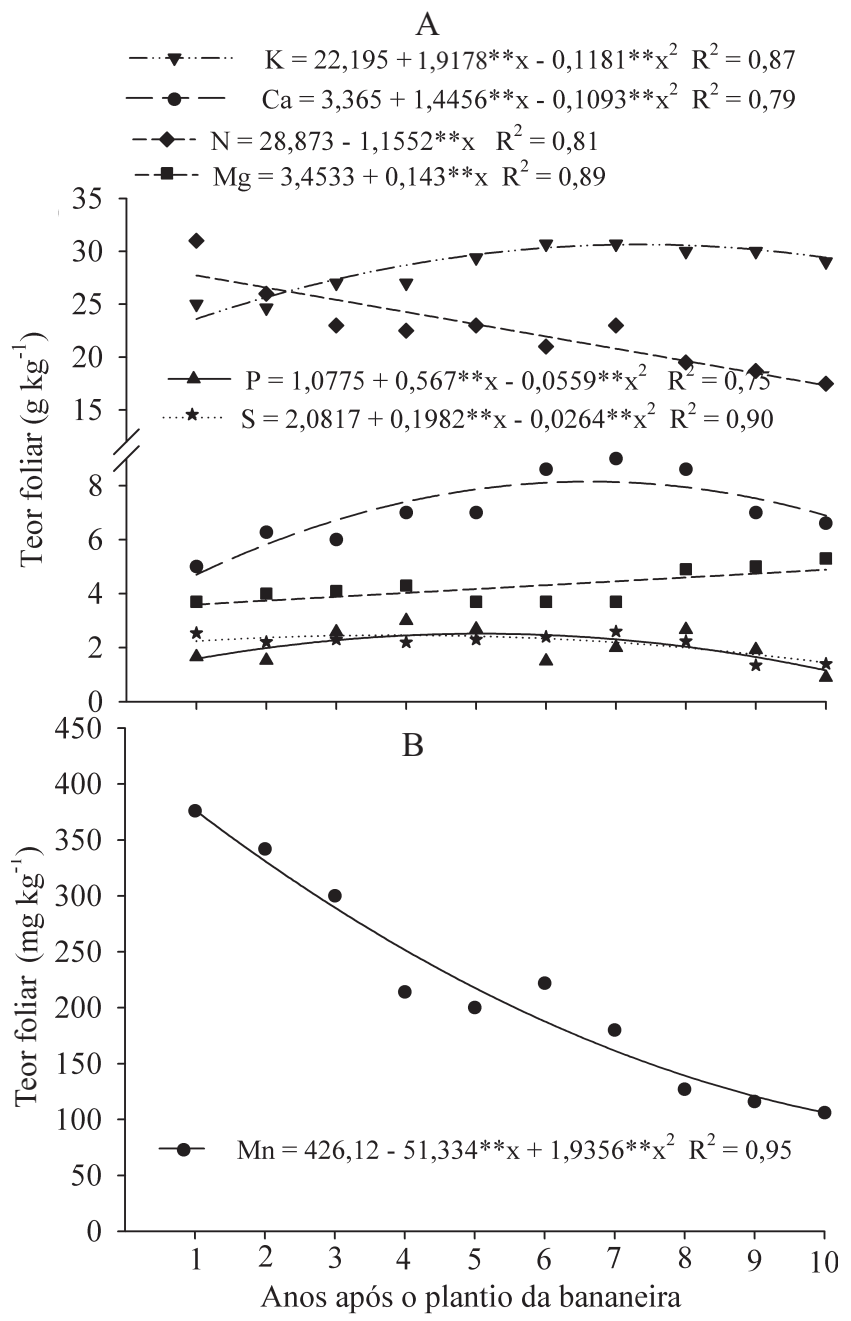

Figura 5. Variação do teor foliar de macronutrientes (A) e Mn (B), em folhas de bananeira cultivar Prata-Anã, ao longo dos anos após o plantio.

Tabela 1. Coeficientes de correlação de Pearson, entre os teores de nutrientes do solo e das folhas, e entre os teores de nutrientes do solo e das folhas e a produtividade da bananeira.

\begin{tabular}{cccc}
\hline Nutriente & $\begin{array}{c}\text { Nutriente do solo } \\
\text { vs. nutriente } \\
\text { da folha }\end{array}$ & $\begin{array}{c}\text { Nutriente do solo } \\
\text { vs. produtividade }\end{array}$ & $\begin{array}{c}\text { Nutriente das } \\
\text { folhas vs. } \\
\text { produtividade }\end{array}$ \\
\hline $\mathrm{Ca}$ & $0,45^{\mathrm{ns}}$ & $0,42^{\mathrm{ns}}$ & $0,55^{\mathrm{ns}}$ \\
$\mathrm{Mg}$ & $0,26^{\mathrm{ns}}$ & $0,40^{\mathrm{ns}}$ & $0,07^{\mathrm{ns}}$ \\
$\mathrm{K}$ & $-0,80^{* *}$ & $-0,47^{\mathrm{ns}}$ & $0,64^{*}$ \\
$\mathrm{P}$ & $0,27^{\mathrm{ns}}$ & $0,56^{\mathrm{ns}}$ & $0,37^{\mathrm{ns}}$ \\
$\mathrm{Mn}$ & $0,96^{* *}$ & $-0,62^{*}$ & $-0,60^{\mathrm{ns}}$ \\
$\mathrm{B}$ & $0,01^{\mathrm{ns}}$ & $0,66^{*}$ & $-0,53^{\mathrm{ns}}$ \\
$\mathrm{Cu}$ & $-0,59^{\mathrm{ns}}$ & $0,44^{\mathrm{ns}}$ & $-0,23^{\mathrm{ns}}$ \\
$\mathrm{Fe}$ & $-0,32^{\mathrm{ns}}$ & $0,54^{\mathrm{ns}}$ & $-0,05^{\mathrm{ns}}$ \\
$\mathrm{Zn}$ & $0,71^{*}$ & $-0,60^{\mathrm{ns}}$ & $-0,80^{* *}$ \\
\hline
\end{tabular}

${ }^{n}$ Não-significativo. * e **Significativo a 5 e $1 \%$ de probabilidade, respectivamente. nutricional das plantas foi o responsável pelas baixas produtividades observadas.

\section{Conclusões}

1. A aplicação da água calcária resulta em forte elevação do $\mathrm{pH}$ e da condutividade elétrica do solo, após dez anos de cultivo da bananeira, e promove desequilíbrios nutricionais que limitam a produtividade da cultura.

2. O grande aporte de $\mathrm{Ca}^{2+}$ e $\mathrm{Mg}^{2+}$ veiculado pela irrigação, ao longo dos dez anos, altera as relações $\mathrm{Ca} / \mathrm{K}$ e $\mathrm{Mg} / \mathrm{K}$ do solo, mas não limita a absorção de nutrientes pela bananeira.

\section{Referências}

ABREU, H.J.M.; MASCRELL, J.; DUART, S.; SOCORRO, A.R. $\mathrm{Na}$ and $\mathrm{Cl}$ content in banana plants of the Canaria Islands. International Banana Nutrition Newsletter, v.15, p.13-14, 1982.

ALVARES VENEGAS, V.H.; NOVAIS, R.F. de; BARROS, N.F. de; CANTARUTTI, R.B.; LOPES, A.S. Interpretação dos resultados das análises de solos. In: RIBEIRO, A.C.; GUIMARÃES, P.T.G.; ALVARES VENEGAS, V.H. (Ed.). Recomendação para o uso de corretivos e fertilizantes em Minas Gerais: 5a Aproximação. Viçosa: CFSEMG, 1999. p.25-32.

BRASIL. Ministério da Agricultura, Pecuária e Abastecimento. Evolução do mercado mundial de frutas. 86p. Disponível em: $\quad<$ http://www.agricultura.gov.br/pls/portal/docs/PAGE/ MAPA/MENU_LATERAL/AGRICULTURA_PECUARIA/ ESTUDOS_PUBLICACOES/ESTUDO_MERCADO_FRUTAS/ CAPITULO_3.PDF>. Acesso em: 15 abr. 2008.

CARMO, G.A. do; MEDEIROS, J.F. de; TAVARES, J.C.; GHEYI, H.R.; SOUZA, A.M. de; PALÁCIO, E.A. de Q. Crescimento de bananeiras sob diferentes níveis de salinidade da água de irrigação. Revista Brasileira de Fruticultura, v.25, p.513-518, 2003.

EMBRAPA. Levantamento exploratório: reconhecimento de solos do Norte de Minas Gerais: área de atuação da Sudene. Recife: Embrapa-SNLCS, 1979. 407p. (Embrapa- SNLCS. Boletim Técnico, $60)$.

EMBRAPA. Manual de métodos de análise de solo. Rio de Janeiro: Embrapa-CNPS, 1997. 212p. (Embrapa-CNPS. Documentos, 1).

FAO. Yearbook Production. Rome: FAO, 2004. v.48. p.164-165. (Statistics Series).

FERREIRA, D.F. SISVAR 4.3: sistema de análises estatísticas. Lavras: Ufla, 1999.

FIGUEIREDO, F.P. de; MANTOVANI, E.C.; SOARES, A.A.; COSTA, L.C.; RAMOS, M.M.; OLIVEIRA, F.G. Produtividade e qualidade da banana 'Prata-Anã', influenciada por lâminas de água, cultivada no Norte de Minas Gerais. Revista Brasileira de Engenharia Agrícola e Ambiental, v.10, p.798-803, 2006.

FONTES, P.S.F.; CARVALHO, A.J.C. de; CEREJA, B.S.; MARINHO, C.S.; MONNERAT, P.H.Avaliação do estado nutricional 
e do desenvolvimento da bananeira 'Prata-Anã' (Musa spp.) em função da adubação nitrogenada. Revista Brasileira de Fruticultura, v.25, p.156-159, 2003.

MAIA, C.E.; MORAIS, E.C. de; OLIVEIRA, M. de. Classificação da água de irrigação utilizando quatro metodologias de cálculo para a razão de adsorção de sódio - II. Região do Baixo Açu, Rio Grande do Norte. Caatinga, v.11, p.47-52, 1998.

MALAVOLTA, E.; VITTI, G.C.; OLIVEIRA, S.A. Avaliação do estado nutricional das plantas: princípios e aplicações. 2.ed. Piracicaba: Potafos, 1997. 201p.

MARTINEZ, H.E.P.; CARVALHO, J.G.; SOUZA, R.B. Diagnose foliar. In: RIBEIRO, A.C.; GUIMARÃES, P.T.G.; ALVARES VENEGAS, V.H. (Ed.). Recomendação para o uso de corretivos e fertilizantes em Minas Gerais: 5a Aproximação. Viçosa: CFSEMG, 1999. 143-168p.

MOREIRA, A.; HEINRICHS, R.; PEREIRA, J.C.R. Densidade de plantio na produtividade e nos teores de nutrientes nas folhas e frutos da bananeira cv. Thap Maeo. Revista Brasileira de Fruticultura, v.29, p.626-631, 2007.

NUNES, W.A.G. de A.; KER, J.C.; NEVES, J.C.L.; RUIZ, H.A.; BEIRIGO, R.M.; BONCOMPANI, A.L.P. Características químicas de solos da região de Janaúba, MG, irrigados com água de poços tubulares e do Rio Gorutuba. Revista Brasileira de Ciência do Solo, v.32, p.227-236, 2008.

PEREIRA, M.C.T.; SALOMÃO, L.C.C.; SILVA, S. de O. e; SEDIYAMA, C.S.; COUTO, F.A.D.; SILVA NETO, S.P. da. Crescimento e produção de primeiro ciclo da bananeira 'Prata-Anã' (AAB) em sete espaçamentos. Pesquisa Agropecuária Brasileira, v.35, p.1377-1387, 2000.

QUAGGIO, J.A. Acidez e calagem em solos tropicais. Campinas: Instituto Agronômico, 2000. 111p.

ROSOLEM, C.A.; BÍSCARO, T. Adsorção e lixiviação de boro em Latossolo Vermelho-Amarelo. Pesquisa Agropecuária Brasileira, v.42, p.1473-1478, 2007.

SILVA, E.B.; RODRIGUES, M.G.V.; SANTOS, J. de O. Estado nutricional de um bananal irrigado com água subterrânea. In:
SIMPÓSIO NORTE MINEIRO SOBRE A CULTURA DA BANANA, 1., 2001, Nova Porteirinha. Anais. Montes Claros: Unimontes, 2001. p.263-276.

SILVA, J.T.A. da; BORGES, A.L.; DIAS, M.S.C.; COSTA, E.L. da; PRUDÊNCIO, J.M. Diagnóstico nutricional da bananeira 'Prata-Anã' para o Norte de Minas. Belo Horizonte: Epamig, 2002. 16p. (Boletim Técnico, 70).

SILVA, J.T.A. da; BORGES, A.L.; MALBURG, J.L. Solos, adubação e nutrição da bananeira. Informe Agropecuário, v.20, p.21-36, 1999.

SILVA, J.T.A. da; PACHECO, D.D.; COSTA, E.L. Atributos químicos e físicos de solos cultivados com bananeira 'Prata-Anã' (AAB), em três níveis de produtividade, no Norte de Minas Gerais.

Revista Brasileira de Fruticultura, v.29, p.102-106, 2007.

SOUZA, M.; GUIMARÃES, P.T.G.; CARVALHO, J.G.; FRAGOAS, J.C. Banana 'Prata-Anã'. In: RIBEIRO, A.C.; GUIMARÃES, P.T.G.; ALVARES VENEGAS, V.H. (Ed.). Recomendação para o uso de corretivos e fertilizantes em Minas Gerais: 5a aproximação. Viçosa: CFSEMG, 1999. p.217-218.

TEIXEIRA, L.A.J.; SPIRONELLO, A.; QUAGGIO, J.A.; FURLANI, P.R. Banana. In: RAIJ, B. van; CANTARELLA, H.; QUAGGIO, J.A.; FURLANI, A.M.C. (Ed.). Recomendações de adubação e calagem para o Estado de São Paulo. Campinas: Fundação IAC, 1997. p.131-132. (Boletim, 100).

VALE, F.R. do; GUILHERME, L.R.G.; GUEDES, G.A. de A.; FURTINI NETO, A.E. Fertilidade do solo: dinâmica e disponibilidade dos nutrientes de plantas. Lavras: Ufla, 1997. $171 \mathrm{p}$.

WANG, M.K.; TZOU, Y.M. Phosphate sorption by calcite and iron-rich calcareous soils. Geoderma, v.65, p.249-261, 1995.

YARON, B. Water suitability for irrigation. In: YARON, E.; DANFORS, E.; VAADID, Y. (Ed.). Arid zone irrigation. Berlin: Springler-Verlag, 1973. p.71-85.

Recebido em 28 de julho de 2008 e aprovado em 31 de outubro de 2008 
